\title{
Using a Computer to Print a Dissertation
}

\begin{abstract}
A program was written for an IBM 1401 computer for the printingout in standard acceptable format of a doctoral dissertation, and a successful pilot project was carried out. Several advantages over conventional typing of dissertations are cited, including simplified correcting of errors and justification of right margin. The only apparent disadvantage is cost, but where free machine time is available there is little if any cost differential.
\end{abstract}

I $T$ IS WIDELY ACCEPTED that the final copy of a dissertation must be typed. With the advent of the computer and its high-speed printer, the typewriter may still be preferred, but it is no longer needed.

To test the capacity of a computer to produce a manuscript acceptable to a university archivist, the second author of this paper wrote a program which printed the dissertation of the first author. The required three copies were run off and accepted by the UCLA archives office. Then two dozen additional copies were run off for binding.

The pilot project was begun after a review of the limits of a mere typewriter for so grand a thing as a dissertation. They include:

1. The typist usually works under severe deadline pressure-the time available between the doctoral committee's acceptance at the final oral exam of the penultimate dissertation copy and the last hour the archivist will accept the completed manuscript in three copies for a graduation in June, or whenever. The hapless candidate cannot begin that last neat version prior to his orals with-

Dr. Fang is National Manager of ABC's News Election Service, Hollywood, California; Mr. Lewis is a Computer Programmer at the University of California, Los Angeles. out some risk, because a committee member's suggestion that a page be deleted here or a footnote added there will ruin the careful sequencing of pages and footnotes.

2. Each page of the finished version is supposed to be letter perfect. The typist who cannot neatly correct an error at the bottom of the page is obliged to retype the whole page.

3 . The right margin of a dissertation manuscript is more ragged than the usual typed report. For this, blame the narrow confines of the dissertation page and the typist's natural reluctance to chance an overstep.

4. Additional copies of the dissertation are expensive, if printed offset; or they are of less than perfect quality, if any of several commercial duplicating processes are used. Here, too, deadline pressures mount as printers in university communities try to keep up with the late May rush.

The present pilot dissertation printed by computer seemed particularly appropriate to its new medium. Its title: "A Computer-Based Analysis of Television News Writing Style for Listening Comprehension." Three computer programs were written in the Autocoder language to print the dissertation.

1. Phase I of The Thesis Writer read punch cards onto tape. 


\section{Phase II of The Thesis Writer} printed the tape.

3. The Program Lister, which is quite simple, printed a tape of the fifteen computer programs used in the analysis.

Each of the three programs used to print the dissertation was written for an IBM 1401 with a $4 \mathrm{~K}$ memory, one tape drive, and such special features as index registers and high-low-equal compare. Two computers with this configuration were available to the authors at the UCLA Computing Facility.

Weeks before the doctoral committee met and, indeed, weeks before the nearly four-hundred-page dissertation was finished, a keypuncher began her work. For convenience, each sentence was punched on a separate card, or on several cards if the sentence ran long. Then the next sentence began on a fresh punch card.

The list of instructions, which forms part of the Phase I program, was varied enough to send the printer to any point on a page and, once there, to print any character, to capitalize, to underline, to overprint, either the same character for a heavier impression or a different character, such as the letter $\mathrm{O}$ with a / through it to distinguish the alphabetic $\mathrm{O}$ from the numerical 0 . The program also superscripted footnote numbers, provided subscripts, switched from double to single spacing, and indented left and/or right. However, the program was not designed to print footnotes at the bottom of the page. Instead, a table of notes was placed at the end of each chapter. It is not impossible to place footnotes. It is inconvenient, so the program was written without that option.

The computer kept track of page numbers and footnote numbers internally; the insertion of an extra footnote in the middle of a chapter required no repunching of subsequent footnote cards. The keypuncher just inserted the sentence containing the extra footnote into the deck, and all the following footnotes in the chapter were automatically bumped up by one. After listing the notes at the end of the chapter, the computer's internal footnote counter was instructed to zero itself in preparation for the next chapter. The page numbering counter, on the other hand, continued to increase. When the computer sensed the bottom of the page, it automatically skipped to the next page, numbered the page in the upper right corner, and proceeded with the printing of the deathless prose. When the signal was given for a new chapter, the page number went to the bottom center of the first page instead of the upper right corner. For the preliminaries of the dissertation, provision was made for Roman numerals and unnumbered pages.

In summary, the computer does almost anything the typewriter does, and does it neater and faster. It is neater in three respects:

1. A keypunch error is corrected by punching a new card, an operation taking a few seconds-about the time needed to type one line. There are no erasures.

2. Margins are justified both left and right. The computer fills a line until it senses a word that will not fit. While that word is reserved for the next line, the computer acts like any veteran linotype operator, placing spaces between the words alternately right and left, starting at the ends to avoid a ragged gap of white down the center of the page. The program provided a simple means of changing to normal spacing for anyone who did not want rightjustification.

3. There is no guesswork about the bottom of the page. The computer printer goes to a preset row, and no further, then skips to the next page.

The cost of using a computer to print a dissertation is certainly important, but at many colleges and universities it will not be the all-pervading factor because a computer may already be available on the premises for student use. If free computer time and free keypunch time 
can be had, the doctoral candidate's costs will be for keypunching, punch cards, and thesis-quality computer double-track paper, assuming that he owns a copy of the object decks of a working program. A competent keypuncher earns about $\$ 2$ an hour. After a little practice with the special characters for paragraphing, underlining, etc., a keypuncher can work almost as fast as a typist, who has her own problems such as erasures. Punch cards are quite cheap. University computer centers may provide them free. Not so with paper. If the archivist requires one copy on 100 per cent rag bond, the candidate may spend, as one of the authors of this article did, some $\$ 300$ for a minimum order, which turned out to be enough rag bond paper for a dozen four-hundred-page copies. The paper consists of continuous-feed sheets with a track along each side which tears away to leave $8 \frac{1}{2} \times 11$ inch pages. The rough edges do not matter; the bookbinder trims all four sides. If the dissertation-by-computer idea were to become popular, the paper cost would drop sharply. Either the paper suppliers or the universities themselves would then stock 100 per cent rag bond, and candidates could buy only as much as they needed.

If computer time had to be paid out of pocket, the cost of printing a dissertation would soar. Using the special chain that prints both upper and lower case letters, the IBM 1401 computer and 1403 printer generate about three pages a minute using Phase II of The Thesis Writer program. One copy of a four-hundred-page dissertation using this program would take more than two hours to print. Prior to the printing, additional hours would be needed to load the punch cards onto tape using the Phase I deck.

It may be said generally that if machine time were free, the cost of printing a dissertation by computer is approximately comparable to established methods, and may indeed be cheaper.

Let us note at this point that universities and private business firms can use their own computers for annual reports and service manuals. This means might be especially attractive to computeroriented companies.

As new as all this may seem, the advances in computer technology can make even this method obsolete before long in both its hardware and software. Input devices for the newest generation of computers, such as IBM's System 360, do away with keypunching. A typist at a special machine types a sentence or a paragraph which appears on a televisiontype monitor in front of her as she types. If she made no typing mistakes she enters the words into the computer by pushing a button. If she has erred, she wipes out her error with her backspace key. With on-line traffic patterns, thirty typists sitting in thirty different rooms could feed thirty dissertations into the same computer at the same time.

To sum it up, the wonderful world of computers can be of service to doctoral and master's candidates. This statement does not imply that the typewriter is a poor machine. It is just that the computer is a better one.

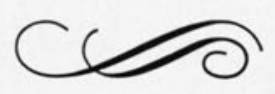

